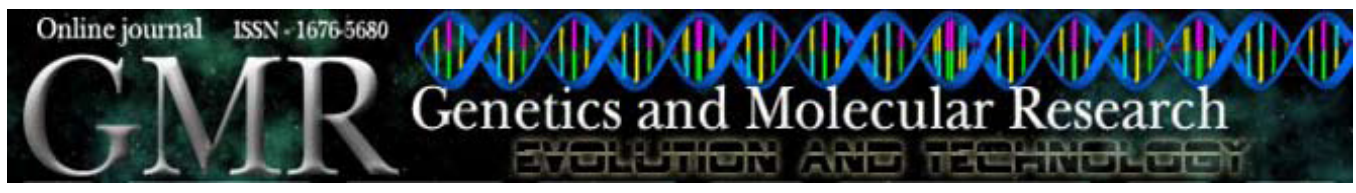

\title{
Genetic population structure and hybridization in two sibling species, Tomoplagia reticulata and Tomoplagia pallens (Diptera: Tephritidae)
}

\author{
A.G. Abreu and V.N. Solferini \\ Departamento de Genética e Evolução, Instituto de Biologia, \\ Universidade Estadual de Campinas, Campinas, SP, Brasil \\ Corresponding author: A.G. Abreu \\ E-mail: agabreu@gmail.com
}

Genet. Mol. Res. 7 (4): 1298-1311 (2008)

Received October 1, 2008

Accepted October 15, 2008

Published November 18, 2008

\begin{abstract}
Tomoplagia reticulata and T. pallens are sibling species that are specialists on Eremanthus glomerulatus. Besides adult terminalia, they show slight morphological differences and distinct geographic distributions. Once, however, they were found sympatrically. Using data from allozyme and mtDNA, we examined patterns of intra- and interspecific genetic structure, and investigated the possible occurrence of gene flow between them. Both species showed low diversity and high genetic structure, which can be linked to their high degree of specialization. Larval development occurs within flower heads, tissues that are available only during a short period of the year. Afterward, as they do not hibernate, they probably suffer a great reduction in population size, which leads to low genetic diversity. As monophagous insects, their population structure may correspond to the fragmented distribution of E. glomerulatus, which could isolate fly populations and increase inbreeding within them. One population exhibited a mixed genetic composition, compatible
\end{abstract}


with one hybridization season when species were sympatric. This hybridization seems to be a rare event, due to T. pallens unusual range expansion.

Key words: Allozymes; Asteraceae; Campo rupestre; Cerrado; Eremanthus glomerulatus; mtDNA

\section{INTRODUCTION}

Close species deriving from a common ancestor may show genetic divergence without conspicuous morphological changes and are classified as sibling species. They are known in all groups of animals, yet they seem to be much more common in some groups, such as parasites and phytophagous insects. Tephritidae (Diptera) is a family of phytophagous comprising more than 4250 species of worldwide distribution (Norrbom et al., 1999). The larvae of most species breed in living plant tissues, such as fruits and flower heads. The subfamilies Trypetinae and Dacinae have been the focus of many studies, because several species are important fruit pests. Much less is known about species of Tephritinae, whose larvae feed in flower heads or vegetative parts of Asteraceae (Headrick and Goeden, 1998). Tomoplagia is a New World and predominantly Neotropical genus of Tephritinae with 45 species described, of which 43 are restricted to Central and South America (Norrbom et al., 1999). In Brazil, Tomoplagia is the most diverse and abundant genus reared from Asteraceae flower heads (Prado et al., 2002).

Abreu et al. (2005) described two sibling species in this genus, Tomoplagia reticulata and T. pallens. They breed on the same host plant, Eremanthus glomerulatus Less (1829), laying their eggs in the flower heads, where the larvae develop. Besides adult terminalia, they show slight morphological differences and distinct geographic distributions. Tomoplagia pallens has a pale yellowish body color, wings with faint markings, and occurs mainly in Goiás State. Tomoplagia reticulata has a dark yellow to orange body color, pigmented wings, and is found only in Minas Gerais State (Abreu et al., 2005).

The host plant, E. glomerulatus (Asteraceae), occurs throughout the central part of Brazil, in Minas Gerais, Goiás, and adjacent regions in Bahia and São Paulo (MacLeish, 1987). It is commonly found in large colonies, in cerrado, that are surrounded by distinct vegetation physiognomies according to their geographic location. In Minas Gerais, the surrounding vegetation is composed of scattered small trees, with a dense grassy ground layer in between. In Goiás, cerrado has a great influence of grassland, corresponding to a rich ground layer (herbs, subshrubs and small shrubs) without trees or with rare small trees, which are much more scattered than in the typical cerrado (Rizzini, 1997).

Over several years of sampling, we never found these two species in sympatry, except for year 2000, when they both were collected in Minas Gerais. This finding led us to investigate whether they display incomplete reproductive isolation when co-occurring. As they can be distinguished by four loci, PGI-1, ME, MDH, and G6PD (Abreu et al., 2005), if they are not fully isolated we would expect some heterozygotes after this contact. Using data from allozyme and mitochondrial DNA (mtDNA), we examined patterns of intra- and interspecific genetic structure of $T$. reticulata and $T$. pallens with the aim of comparing levels of differentiation between parasites of the same host, and investigating a possible occurrence of gene flow between this pair of closely related species, when in sympatry. 


\section{MATERIAL AND METHODS}

\section{Collection of material}

Flower heads of Eremanthus glomerulatus were collected during 4 consecutive seasons of flowering, from 1999 to 2002, and placed in plastic jars covered with a cotton cloth. After emergence, adults were fed for four days with honey and water and then frozen in liquid nitrogen until genetic analysis.

The localities sampled are shown in Figure 1. Sample identifications, sizes and years are summarized in Table 1. As herbivore demes can be adapted to individual host plants (reviewed in Mopper and Strauss, 1998), we pre-defined a population as all flies emerging from flower heads of a single tree. T. pallens was sampled in Brasília (Distrito Federal), Goiás and, only in the year 2000, Santana do Riacho (Minas Gerais), whereas T. reticulata was sampled only in Santana do Riacho (Minas Gerais). The samples SR-1, SR-3, GO-1, GO-2, and BSB-2 had already been investigated for allozyme polymorphism by Abreu et al. (2005).

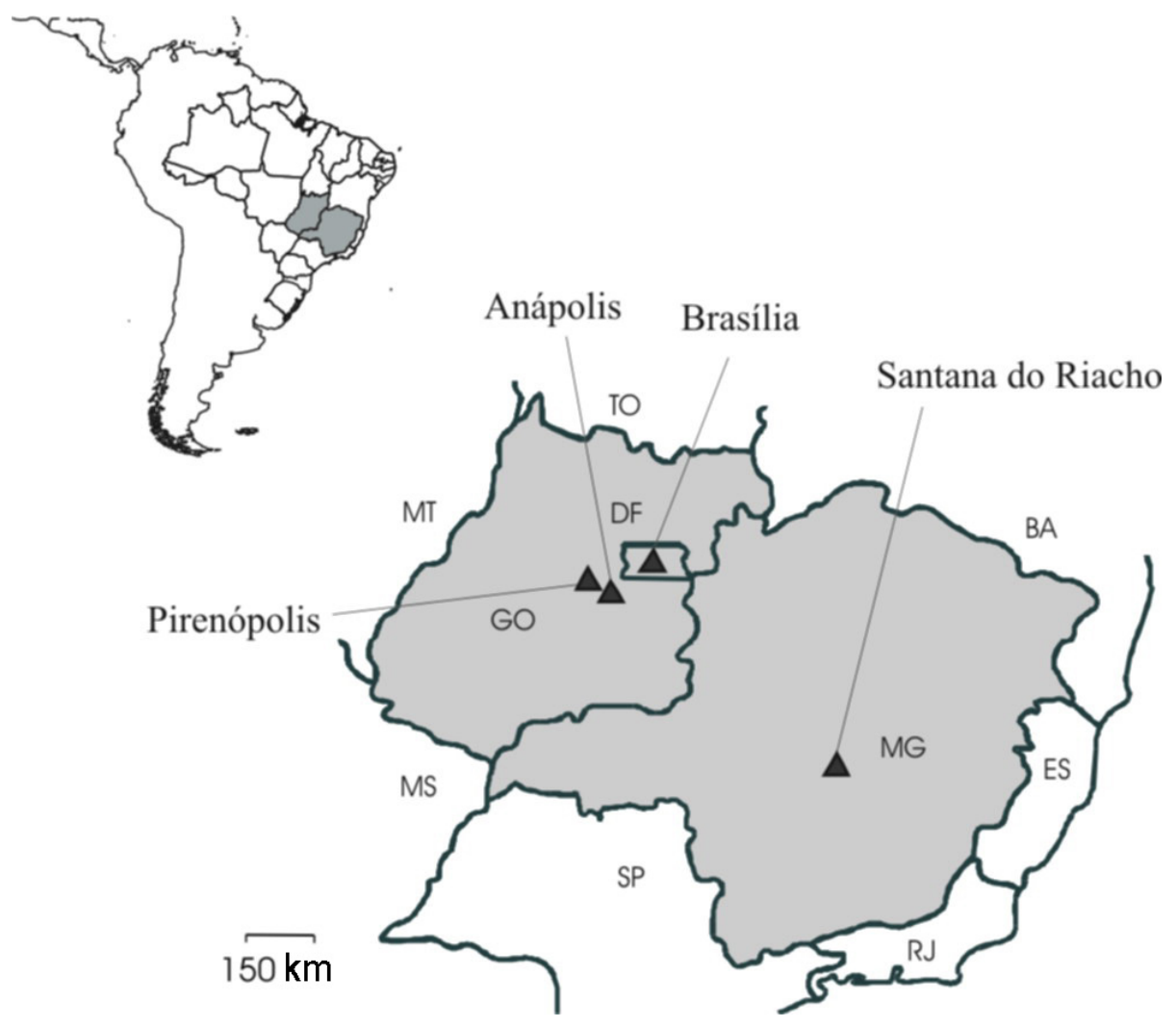

Figure 1. Sampling localities. See Table 1 for sample names. $\mathrm{BA}=$ Bahia; $\mathrm{GO}=$ Goiás; $\mathrm{MG}=$ Minas Gerais; $\mathrm{SP}=\mathrm{São}$ Paulo; ES = Espírito Santo; MS = Mato Grosso do Sul; RJ = Rio de Janeiro; MT = Mato Grosso; DF = Distrito Federal. 


\begin{tabular}{|c|c|c|c|c|c|c|}
\hline Species & Locality (State) & Sample code & Sampling year & Coordinates & Allozyme (N) & $\operatorname{RFLP}(\mathrm{N})$ \\
\hline \multirow[t]{16}{*}{ T. pallens } & \multirow[t]{4}{*}{ Brasília (DF) } & BSB-1 & 1999 & $15^{\circ} 36^{\prime} 24^{\prime \prime} \mathrm{S} 47^{\circ} 34^{\prime} 32^{\prime \prime} \mathrm{W}$ & 55 & 31 \\
\hline & & BSB-2 & 2001 & $15^{\circ} 36^{\prime} 50^{\prime \prime} \mathrm{S} 47^{\circ} 41^{\prime} 30^{\prime \prime} \mathrm{W}$ & 25 & 30 \\
\hline & & BSB-3 & 2002 & $15^{\circ} 40^{\prime} 50^{\prime \prime} \mathrm{S} 47^{\circ} 52^{\prime} 03^{\prime \prime} \mathrm{W}$ & - & 30 \\
\hline & & BSB-4 & 2002 & $15^{\circ} 42^{\prime} 17^{\prime \prime S} 47^{\circ} 52^{\prime} 38^{\prime \prime} \mathrm{W}$ & - & 24 \\
\hline & Pirenópolis (GO) & GO-1 & 2001 & $15^{\circ} 53^{\prime} 30^{\prime \prime} \mathrm{S} 48^{\circ} 53^{\prime} 19^{\prime \prime} \mathrm{W}$ & 32 & 29 \\
\hline & \multirow[t]{8}{*}{ Anápolis (GO) } & GO-2 & 2001 & $16^{\circ} 03^{\prime} 49^{\prime \prime S} 48^{\circ} 51^{\prime} 15^{\prime \prime} \mathrm{W}$ & 34 & 30 \\
\hline & & GO-3 & 2001 & $16^{\circ} 12^{\prime} 05^{\prime \prime} \mathrm{S} 48^{\circ} 54^{\prime} 39^{\prime \prime} \mathrm{W}$ & 34 & 29 \\
\hline & & GO-4 & 2001 & $16^{\circ} 12^{\prime} 05^{\prime \prime} \mathrm{S} 48^{\circ} 54^{\prime} 39^{\prime \prime} \mathrm{W}$ & - & 30 \\
\hline & & GO-5 & 2001 & $16^{\circ} 13^{\prime} 14^{\prime \prime} \mathrm{S} 48^{\circ} 55^{\prime} 20^{\prime \prime} \mathrm{W}$ & 31 & 30 \\
\hline & & GO-6 & 2001 & $16^{\circ} 24^{\prime} 27^{\prime \prime S} 48^{\circ} 59^{\prime} 08^{\prime \prime} \mathrm{W}$ & 41 & 30 \\
\hline & & GO-7 & 2002 & $16^{\circ} 13^{\prime} 16^{\prime \prime} \mathrm{S} 48^{\circ} 55^{\prime} 22^{\prime \prime} \mathrm{W}$ & - & 25 \\
\hline & & GO-8 & 2002 & $16^{\circ} 12^{\prime} 06^{\prime \prime S} 48^{\circ} 54^{\prime} 40^{\prime \prime} \mathrm{W}$ & - & 30 \\
\hline & & GO-9 & 2002 & $16^{\circ} 02^{\prime} 38^{\prime \prime S} 48^{\circ} 51^{\prime} 07^{\prime \prime} \mathrm{W}$ & - & 20 \\
\hline & Pirenópolis (GO) & GO-10 & 2002 & $15^{\circ} 53^{\prime} 36^{\prime \prime} \mathrm{S} 48^{\circ} 52^{\prime} 52^{\prime \prime} \mathrm{W}$ & - & 30 \\
\hline & Santana do Riacho (MG) & SRp-1 & 2000 & $19^{\circ} 17^{\prime} 58^{\prime \prime S} 43^{\circ} 36^{\prime} 08^{\prime \prime} \mathrm{W}$ & 24 & - \\
\hline & Santana do Riacho (MG) & SRp-2 & 2000 & $19^{\circ} 17^{\prime} 29^{\prime \prime} \mathrm{S} 43^{\circ} 36^{\prime} 06^{\prime \prime} \mathrm{W}$ & 3 & - \\
\hline \multirow[t]{9}{*}{ T. reticulata } & \multirow[t]{9}{*}{ Santana do Riacho (MG) } & SRr-1 & 2000 & $19^{\circ} 17^{\prime} 58^{\prime \prime} \mathrm{S} 43^{\circ} 36^{\prime} 08^{\prime \prime} \mathrm{W}$ & 24 & - \\
\hline & & SRr-2 & 2000 & $19^{\circ} 17^{\prime} 29^{\prime \prime S} 43^{\circ} 36^{\prime} 06^{\prime \prime} \mathrm{W}$ & 47 & 24 \\
\hline & & SR-3 & 2001 & $19^{\circ} 17^{\prime} 58^{\prime \prime} \mathrm{S} 43^{\circ} 36^{\prime} 08^{\prime \prime} \mathrm{W}$ & 32 & 30 \\
\hline & & SR-4 & 2001 & $19^{\circ} 17^{\prime} 58^{\prime \prime S} 43^{\circ} 36^{\prime} 08^{\prime \prime} \mathrm{W}$ & - & 20 \\
\hline & & SR-5 & 2001 & $19^{\circ} 17^{\prime} 51^{\prime \prime S} 43^{\circ} 36^{\prime} 09^{\prime \prime} \mathrm{W}$ & - & 20 \\
\hline & & SR-6 & 2001 & $19^{\circ} 17^{\prime} 29^{\prime \prime} \mathrm{S} 43^{\circ} 36^{\prime} 06^{\prime \prime} \mathrm{W}$ & - & 30 \\
\hline & & SR-7 & 2002 & $19^{\circ} 17^{\prime} 56^{\prime \prime} \mathrm{S} 43^{\circ} 36^{\prime} 09^{\prime \prime} \mathrm{W}$ & - & 21 \\
\hline & & SR-8 & 2002 & $19^{\circ} 17^{\prime} 28^{\prime \prime} \mathrm{S} 43^{\circ} 36^{\prime} 06^{\prime \prime} \mathrm{W}$ & - & 17 \\
\hline & & SR-9 & 2002 & $19^{\circ} 17^{\prime} 28^{\prime \prime S} 43^{\circ} 36^{\prime} 06^{\prime \prime} \mathrm{W}$ & 27 & 28 \\
\hline
\end{tabular}

\section{Allozyme analysis}

The tissues were homogenized in $30 \mu \mathrm{L}$ system III gel solution (see below). The extract of each fly was absorbed onto filter paper wicks (Whatman \#1) and then applied to an $8.5 \%$ starch gel (Sigma). Three buffer systems were used: I) electrode: $0.3 \mathrm{M}$ boric acid, $60 \mathrm{mM} \mathrm{NaOH}, \mathrm{pH}$ 8.0; gel: $10 \mathrm{mM}$ Tris, $\mathrm{pH}$ 8.5; II) electrode: $10 \mathrm{mM} \mathrm{LiOH}$, $3 \mathrm{mM}$ EDTA and $90 \mathrm{mM}$ boric acid, $\mathrm{pH}$ 8.0; gel: electrode solution diluted 1:10, and III) electrode: $0.34 \mathrm{M}$ Tris, $78 \mathrm{mM}$ citric acid, $\mathrm{pH}$ 8.6; gel: $38 \mathrm{mM}$ Tris, $2.5 \mathrm{mM}$ citric acid, $\mathrm{pH}$ 8.6. System I was used for esterase (EST - EC 3.1.1.1), aconitase (ACO - EC 4.2.1.3), 3-hydroxybutyrate dehydrogenase (HBDH - EC 1.1.1.30), glutamate dehydrogenase (GDH - EC 1.4.1.3), and leucylalanine peptidase (PEP - EC 3.4.11); system II was used for phosphoglucose isomerase (PGI - EC 5.3.1.9), 6-phosphogluconate dehydrogenase (6PGD - EC 1.1.1.44), glucose 6-phosphate dehydrogenase (G6PD - EC 1.1.1.49), and fumarase (FUM - EC 4.2.1.2), and system III was used for isocitrate dehydrogenase (IDH - EC 1.1.1.42), phosphoglucomutase (PGM - EC 5.4.2.2.), malate dehydrogenase (MDH - EC 1.1.1.37), malic enzyme (ME - EC 1.1.1.40), and aldehyde oxidase (AO - EC 1.2.3.1). When there was more than one locus, they were numbered in ascending order from the locus with lowest mobility. The alleles were scored according to their mobility relative to the most common allele of sample BSB-1. The allele frequencies at enzyme loci were calculated by direct counting of alleles. 


\section{Mitochondrial DNA analysis}

Total DNA was extracted from frozen specimens. A modified phenol-chloroform extraction (Azeredo-Espin et al., 1991) was used. A 2325-bp fragment of the mitochondrial genes cytochrome oxidase I and II (COI/COII) was amplified using the primers TY-J-1460 and TK-N-3785 described by Simon et al. (1994). Three microliters of total DNA solution was used as template in $75-\mu \mathrm{L}$ reactions containing $3.5 \mathrm{mM} \mathrm{MgCl}_{2}, 0.2 \mathrm{mM}$ dNTP, $0.4 \mu \mathrm{M}$ each primer and $3 \mathrm{U}$ Taq DNA polymerase. Polymerase chain reaction (PCR) conditions were as follows: 4 min at $94^{\circ} \mathrm{C} ; 35$ cycles of denaturation at $94^{\circ} \mathrm{C}$ for $30 \mathrm{~s}$, annealing at $58^{\circ} \mathrm{C}$ for $60 \mathrm{~s}$ and extension at $71^{\circ} \mathrm{C}$ for $2 \mathrm{~min}$, and a final extension cycle at $71^{\circ} \mathrm{C}$ for $4 \mathrm{~min}$.

Eight microliters PCR product was digested for $2 \mathrm{~h}$, at $37^{\circ} \mathrm{C}$ with $1 \mathrm{U}$ enzyme in the appropriate buffer. DNA fragments were digested with six endonucleases (DdeI, EcoRV, HaeIII, PvuII, RsaI, and XbaI). Electrophoresis was performed on $2.5 \%$ agarose gels, which were stained with ethidium bromide, and visualized under ultraviolet light.

\section{Statistical methods}

\section{Allozymes}

Measures of genetic diversity (percentage of polymorphic loci, mean number of alleles per locus, and the observed and expected heterozygosity) were estimated using the GENETIX 4.05.2 program (Belkhir et al., 1996-2004). F-statistics (Wright, 1951) were calculated by the method of Weir and Cockerham (1984) (estimators $\theta$ and $f$ ), and their significance (5\% level) was tested by bootstrapping using GeNETIX 4.05.2 (Belkhir et al., 2004). Tests for deviations from Hardy-Weinberg equilibrium (by exact tests) and for linkage disequilibrium were calculated using the GENEPOP 3.3 software (Raymond and Rousset, 1995). The sequential Bonferroni was used to correct for multiple comparisons. Genetic divergence among samples was estimated from allele frequencies with the method of Nei (1978) using GeNETIX 4.05.2 (Belkhir et al., 2004), and these distances were subjected to neighbor-joining cluster analyses using the MEGA 3.1 software (Kumar et al., 2004).

\section{Polymerase chain reaction-restriction fragment length polymorphism}

Data from restriction site patterns were analyzed using the ARLEQUIN software (Excoffier et al., 2005). Intra- and intersample genetic diversity were measured by haplotype and nucleotide diversity ( $h$ and $\pi$; Nei, 1987), Nei's raw (D) and net $\left(\mathrm{D}_{\mathrm{A}}\right)$ intersample nucleotide divergence (Nei and Li, 1979). The matrix of net intersample nucleotide divergence was used to build a neighbor-joining phenogram of the samples using MEGA 3.1 (Kumar et al., 2004). To investigate the genetic structure of samples, we performed an analysis of molecular variance (AMOVA).

The assignment of individuals to populations and the individual admixture proportion were implemented in the STRUCTURE program (Falush et al., 2007). The model probabilistically assigns individuals to source clusters (or jointly to two or more clusters in cases of admixture) on the basis of their genotypes. Twenty independent runs were carried out for each value of $K(K$ from 1 to 6 ) of clusters. For each run, 500,000 iterations were carried out after a burn-in period of 50,000 iterations. The true value of $K$ was chosen on the basis of the second order rate of change of the log likelihood function with respect to $K(\Delta K$; Evanno et al., 2005). Analyses were initially 
performed without prior assumptions concerning the population (phenotype or geographic location). Simulations were then carried out for $K=2$ (2 clusters), using yellow and orange phenotypes (yellow - T. pallens and orange - T. reticulata) as prior information for clustering, and the probability of admixture in the last four generations was inferred for each specimen.

\section{RESULTS}

\section{Allozyme variation}

Only samples SR-1 and SR-2 showed both species. Ten loci (of 17 screened) were polymorphic in both species and four of them (MDH, PGI-1, G6PD, and $M E)$ distinguished the two species (Table 2). T. pallens exhibited lower variation than $T$. reticulata (Table 2 ). The fixation index $(\theta)$ was $0.069( \pm 0.047)$ in T. pallens, and $0.117( \pm 0.061)$ in T. reticulata, which indicates genetic differentiation among the samples of each species.

\begin{tabular}{|c|c|c|c|c|c|c|c|c|c|c|c|c|c|c|}
\hline \multirow[t]{2}{*}{ Locus } & \multirow[t]{2}{*}{ Allele } & \multicolumn{4}{|c|}{ T. reticulata } & \multicolumn{9}{|c|}{ T. pallens } \\
\hline & & SRr-1 & SRr-2 & SR-3 & SR-9 & SRp-1 & SRp-2 & BSB-1 & BSB-2 & GO-1 & GO-2 & GO-3 & GO-5 & GO-6 \\
\hline \multirow[t]{4}{*}{$M E$} & 0.78 & 0.50 & 0.33 & 0.50 & 0.52 & 0.07 & - & - & - & - & 0.03 & - & - & - \\
\hline & 0.90 & 0.50 & 0.58 & 0.50 & 0.48 & 0.29 & - & 0.14 & - & - & - & - & 0.03 & - \\
\hline & 1.00 & - & 0.09 & - & - & 0.43 & 1.00 & 0.81 & 0.96 & 1.00 & 0.94 & 0.91 & 0.97 & 1.00 \\
\hline & 1.05 & - & - & - & - & 0.21 & - & 0.05 & 0.04 & - & 0.03 & 0.09 & - & - \\
\hline \multirow[t]{3}{*}{$P G I-1$} & 0.33 & - & - & - & - & - & - & - & 0.04 & 0.06 & - & - & - & 0.02 \\
\hline & 1.00 & - & 0.06 & 0.02 & 0.04 & 1.00 & 0.83 & 0.95 & 0.96 & 0.94 & 1.00 & 1.00 & 1.00 & 0.98 \\
\hline & 3.90 & 1.00 & 0.94 & 0.98 & 0.96 & - & 0.17 & 0.05 & - & - & - & - & - & - \\
\hline \multirow[t]{4}{*}{$M D H$} & 0.75 & 0.57 & 0.76 & 0.67 & 1.00 & - & - & 0.07 & 0.02 & 0.02 & - & - & - & - \\
\hline & 0.82 & 0.43 & 0.24 & 0.33 & - & - & - & - & - & - & - & 0.02 & 0.03 & - \\
\hline & 1.00 & - & - & - & - & 1.00 & 1.00 & 0.93 & 0.98 & 0.91 & 1.00 & 0.98 & 0.97 & 0.97 \\
\hline & 1.15 & - & - & - & - & - & - & - & - & 0.07 & - & - & - & 0.03 \\
\hline \multirow[t]{2}{*}{$G 6 P D$} & 0.84 & 1.00 & 0.88 & 1.00 & 0.94 & - & - & - & - & - & - & - & - & - \\
\hline & 1.00 & - & 0.12 & - & 0.06 & 1.00 & 1.00 & 1.00 & 1.00 & 1.00 & 1.00 & 1.00 & 1.00 & 1.00 \\
\hline P & & 46.7 & 41.2 & 23.5 & 23.5 & 33.3 & 16.7 & 33.3 & 17.6 & 29.4 & 23.5 & 29.4 & 29.4 & 11.8 \\
\hline $\mathrm{H}_{\mathrm{e}}$ & & 0.195 & 0.188 & 0.131 & 0.080 & 0.146 & 0.06 & 0.149 & 0.103 & 0.090 & 0.072 & 0.087 & 0.080 & 0.061 \\
\hline (SD) & & $(0.38)$ & $(0.40)$ & $(0.23)$ & $(0.16)$ & $(0.41)$ & (0.66) & $(0.40)$ & $(0.18)$ & $(0.18)$ & $(0.17)$ & $(0.17)$ & $(0.16)$ & $(0.14)$ \\
\hline A & & 1.6 & 1.8 & 1.5 & 1.5 & 1.6 & 1.2 & 2.1 & 1.8 & 1.7 & 1.7 & 1.8 & 1.8 & 1.8 \\
\hline$f$ & & 0.81 & 0.82 & 0.67 & 0.83 & 0.90 & 0 & 0.72 & 0.63 & 0.53 & 0.58 & 0.62 & 0.45 & 0.41 \\
\hline
\end{tabular}

Genetic variability ( $\mathrm{P}=$ proportion of polymorphic loci, $\mathrm{H}=$ mean expected heterozygosity + standard deviation $(\mathrm{SD}) ; \mathrm{A}=$ mean number of alleles per locus) and inbreeding coefficient $(f)$ at all allozyme loci for Tomoplagia reticulata and $T$. pallens.

Significant departures from the Hardy-Weinberg equilibrium (at 5\% significance level), in at least one sample, were detected in both species: in $T$. reticulata, in the loci $M E, M D H, P G M, 6 P G D$, and G6PD, and in T. pallens in ACO, AO, ME, MDH, PGM, and $6 P G D$. All significant deviations had positive $f$ values, indicating deficiencies of heterozygote. Mean $f$ value was $0.549( \pm 0.214)$ in T. pallens and $0.798( \pm 0.113)$ in $T$. reticulata. There was linkage disequilibrium only in T. reticulata, between loci $M E-M D H$ in sample SRr-2 and $I D H-M D H$ in SR-3. 
Genetic relationships between samples are presented in Figure 2. Mean genetic identity was 0.764 between species. The intraspecific identities ranged from 0.928 to 1 among T. pallens samples and from 0.966 to 0.982 in T. reticulata. SRp-1 and SRp-2 were the samples with higher differences to other conspecific samples (BSB and GO). In diagnostic loci PGI-1 and G6PD (according to Abreu et al., 2005), each species had its typical allele fixed or very nearly fixed. Exceptions were populations SRr-2 and SR-9, which had pallens alleles in both loci, mostly in heterozygosis, and SRp-2, which had one heterozygous individual in PGI-1 (Figure 2).

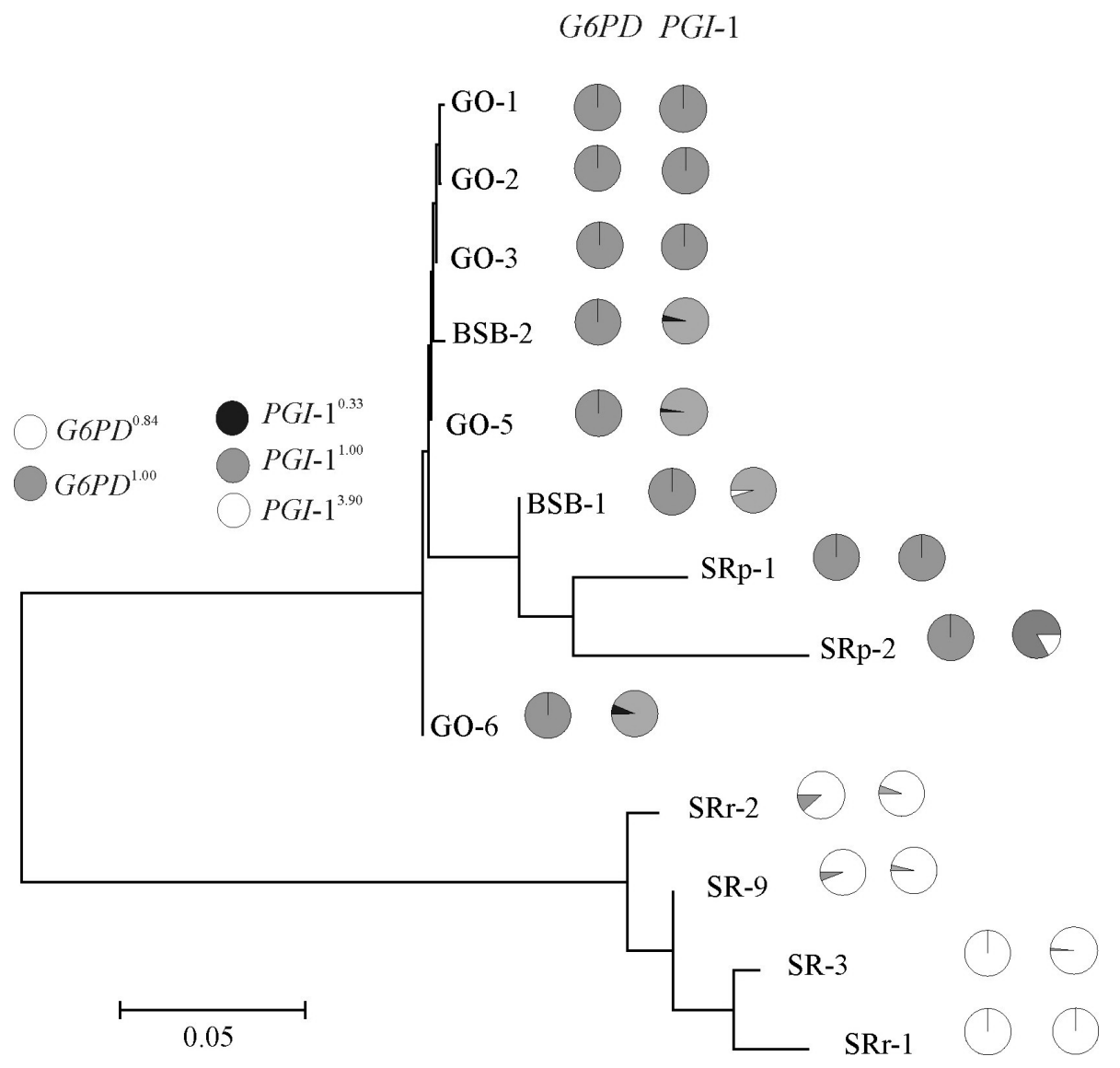

Figure 2. Neighbor-joining cluster analysis based on Nei's (1978) genetic distance estimated among the samples of Tomoplagia pallens and T. reticulata, using allozyme data. Pie diagrams indicate allele frequency of G6PD and PGI-1 loci.

\section{Mitochondrial DNA variation analysis}

The enzyme $D d e \mathrm{I}$ had 6 restriction patterns; HaeIII, 3; PvuII, 2; EcoRV, 4; XbaI, 
2, and RsaI, 2, totalizing 15 restriction sites and 24 composite haplotypes (A-X). In $T$. pallens, there were 15 haplotypes; haplotype A was the most frequent in all samples. In $T$. reticulata, there were 11 haplotypes and the most frequent was J, except for sample SR-5. Only haplotypes A and B were found in both species, A at very high frequencies in T. pallens, and B at low frequencies in both species. Some specimens of samples SRr-2, SR-4 and SR-5, morphologically assigned to T. reticulata, had haplotype A (Figure 3).

Measures of genetic diversity are shown in Table 3. Both the nucleotide and haplotype diversity varied among samples of the two species. As in allozymes, T. reticulata showed higher variability, especially sample SR-2, which had the greatest values for both diversity measures. T. reticulata showed greater sample differentiation $\left(\phi_{\mathrm{ST}}=0.237\right)$ than $T$. pallens $\left(\phi_{\mathrm{ST}}=0.111\right)$, and the larger part of the observed variation was within samples in both species (76.30 and $88.97 \%$, respectively), according to AMOVA.

Table 3. Haplotype $(h)$ and nucleotide diversity $(\pi)$ of Tomoplagia pallens and T. reticulata samples.

\begin{tabular}{lcc}
\hline Sample & Haplotype diversity (SD) & Nucleotide diversity (SD) \\
\hline BSB-1 & $0.615(0.096)$ & $0.096(0.065)$ \\
BSB-2 & $0.453(0.104)$ & $0.058(0.046)$ \\
BSB-3 & $0.193(0.095)$ & $0.012(0.018)$ \\
BSB-4 & $0.235(0.109)$ & $0.020(0.024)$ \\
GO-1 & $0.254(0.100)$ & $0.033(0.031)$ \\
GO-2 & $0.067(0.061)$ & $0.004(0.009)$ \\
GO-3 & $0.191(0.093)$ & $0.012(0.017)$ \\
GO-4 & $0.067(0.061)$ & $0.004(0.010)$ \\
GO-5 & $0.067(0.061)$ & $0.004(0.010)$ \\
GO-6 & $0.067(0.061)$ & $0.008(0.014)$ \\
GO-7 & $0.347(0.108)$ & $0.022(0.025)$ \\
GO-8 & $0.067(0.061)$ & $0.008(0.014)$ \\
GO-9 & $0.521(0.042)$ & $0.032(0.032)$ \\
GO-10 & $0.067(0.061)$ & $0.004(0.010)$ \\
SRr-2 & $0.670(0.043)$ & $0.137(0.087)$ \\
SR-3 & $0.637(0.081)$ & $0.102(0.068)$ \\
SR-4 & $0.279(0.123)$ & $0.035(0.033)$ \\
SR-5 & $0.419(0.127)$ & $0.076(0.055)$ \\
SR-6 & $0.480(0.053)$ & $0.076(0.057)$ \\
SR-7 & $0.467(0.112)$ & $0.080(0.057)$ \\
SR-8 & $0.118(0.101)$ & $0.020(0.024)$ \\
SR-9 & $0.542(0.070)$ & $0.093(0.063)$ \\
\hline
\end{tabular}

In parentheses, the standard deviation (SD).

Nucleotide divergence was higher among samples of T. reticulata than of T. pallens. SRr-2 was the T. reticulata sample that showed the highest similarity with $T$. pallens samples, being in some cases closer to samples of the other species (SRr-2-BSB-1 = $0.840)$ than to its own $(\mathrm{SRr}-2-\mathrm{SR}-5=1.146)$. In the phenogram (Figure 3), samples SR-5 and GO-9 are apart from the others, with longer branches. SR-5 is the only T. reticulata sample in which the most frequent haplotype is not $\mathrm{J}$ but $\mathrm{Q}$. GO-9 has haplotype $\mathrm{M}$ in almost the same frequency as A. In other T. pallens samples, haplotype $\mathrm{A}$ is the most frequent and the other ones are in a very low frequency. 


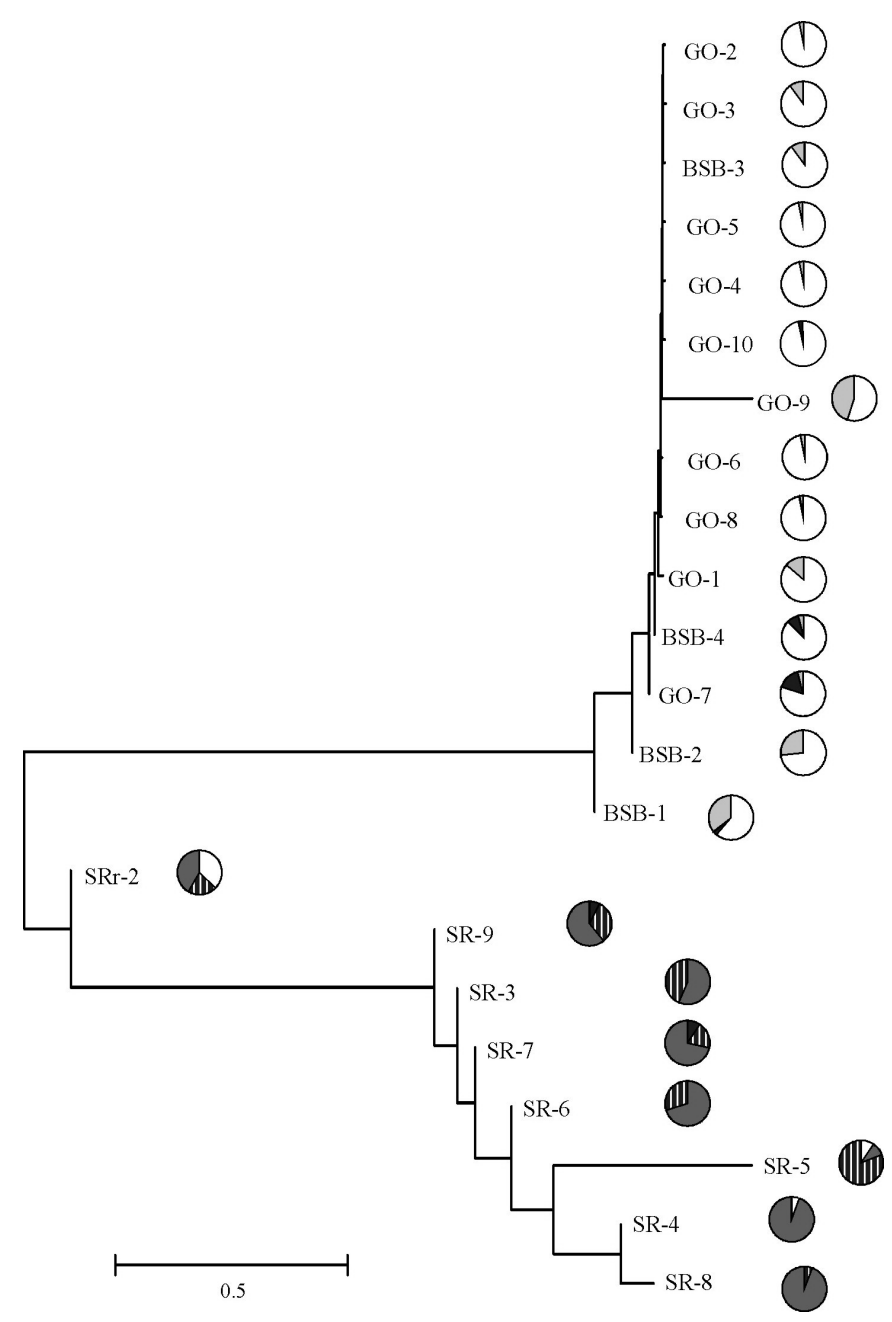

Figure 3. Neighbor-joining cluster analysis based on net intersample nucleotide divergence among Tomoplagia reticulata and T. pallens samples, using mtDNA data. Pie diagrams indicate haplotype frequency of the following categories: shared haplotypes between species, A (most frequent haplotype in T. pallens - white) and B (black); most frequent haplotype in $T$. reticulata (dark gray), pooled rare haplotypes in T. reticulata (hatched); pooled rare haplotypes in T. pallens (light gray).

Cluster analysis with the STRUCTURE software revealed that the most likely genetic structure for the whole data set consisted of two clusters $(\Delta K=2)$. One grouped all eight populations displaying T. reticulata morphology, and the other, the fourteen populations with T. pallens phenotype. When we used phenotypic information as prior clustering information $(K=2), 99.5 \%$ (397/399) of the T. pallens specimens and 91.62\% (175/191) of the T. reticulata specimens were assigned to the appropriate cluster with a probability $\geq 0.90$. The remaining 2 pallens individuals (2 BSB-1) and 16 reticulata individuals (9 SRr-2, 1 SR-4, 2 SR-5, 2 SR-7, and 2 SR-9) had an assignment probability below 0.90 , indicative of mixed ancestry (Figure 4 ). 


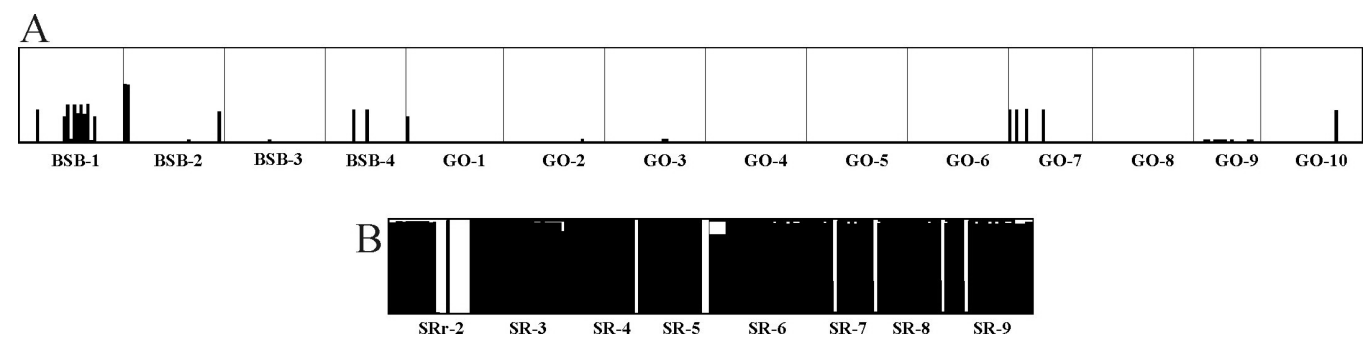

Figure 4. Best clustering result and detection of hybrids $(K=2)$ by the STRUCTURE software, using mtDNA data. Each individual is represented as a vertical line partitioned into colored segments, the length of which is proportional to the individual's estimated $K$ cluster membership coefficients. A. Tomoplagia pallens samples. B. T. reticulata samples.

\section{DISCUSSION}

The Tephritid life cycle is closely associated with the host plants. They spend most of their lifetime on them or in parts thereof, and the most intimate part of the life cycle is larval development, which occurs within living plant tissues. Some of these tissues, such as flowers and fruits, are available only during a short period of the year. Polyphagous species can use other hosts when the main resource is scarce but specialists do not have any choice (Fitt, 1986; Aluja and Birke, 1993). Their peak oviposition should be synchronized with the peak flowering/fruiting of the host plant (Zwölfer, 1982), and afterward, either the species hibernate until the next favorable period or they will suffer a great reduction in population size. E. glomerulatus has a flowering period from March to October, having few flowers during the rest of the year. There are no studies describing Tomoplagia's life cycle, but our own observations indicate that adults live for around 30 days and females start mating and laying eggs only one week after emergence.

Data on other tephritids suggest that tropical species are multivoltine and do not have diapause (Bateman, 1972). In this way, T. reticulata and T. pallens may have a peak population during peak flowering and then experience a great reduction in population size between flowering periods. These annual and recurrent size fluctuations are expected to lead to low genetic diversity in both $T$. pallens and T. reticulata. Indeed, the allozyme genetic diversity observed in T. pallens $\left(\mathrm{H}_{\mathrm{e}}=0.094\right)$ and T. reticulata $(0.148)$ is lower than in other Tephritinae that have diapause during winter. Urophora cardui induces galls on Circium arvense; the larvae overwinter in galls and adults emerge in summer (Peschken and Harris, 1975). U. cardui has an $\mathrm{H}_{\mathrm{e}}$ between 0.29 and 0.32 (Johannesen and Seitz, 2003). Tephritis bardanae is an achene parasite of Arctium that hibernates, right after emergence, for up to 200 days (Straw, 1989) and has an $\mathrm{H}_{\mathrm{e}}$ of 0.127-0.232 (Eber et al., 1991).

When we compared genetic diversity between them, T. pallens had a lower genetic diversity, using both allozymes and mtDNA. As T. pallens has a broad geographic distribution and lower inbreeding levels $(f)$, this was not expected. This low nuclear and mtDNA diversity could be a sign of a recent demographic expansion. T. pallens also showed a haplotype network with limited divergence among the existing haplotype variants (star-like). According to Avise (2000), this network shape is usually interpreted as 
the signature of a recent population expansion, reinforcing the hypothesis of recent demographic expansion in this species.

Both species showed moderate to high genetic structure. As monophagous insects, their population structure may correspond to the fragmented distribution of E. glomerulatus. Host plant structure influences movement patterns of herbivores within and among patches, and therefore, it also has an effect on their population structure (McCauley, 1987). The host's fragmented distribution could isolate fly populations and increase inbreeding within them and genetic differentiation between them, as seen in other studies on invertebrates (e.g., Britten and Rust, 1996; Keyghobadi et al., 1999; Britten et al., 2003).

When we compared the genetic structure between parasites, T. pallens showed less structure than T. reticulata. Samples of T. pallens were taken from trees that were up to $663 \mathrm{~km}$ apart and T. reticulata was sampled along $0.9 \mathrm{~km}$. Minas Gerais has a high topographic relief compared to the plateau area of Goiás, and the vegetation around $E$. glomerulatus patches is denser in Minas Gerais than in Goiás. The higher genetic structure in $T$. reticulata could be due to efficient physical barriers between patches, which would restrict the movement of flies, promoting genetic differentiation between populations. Roland et al. (2000) found that forests were twice as resistant to butterfly movement as meadows. Besides physical barriers, it seems that T. pallens can migrate longer distances than $T$. reticulata, as it reached $T$. reticulata distribution but the opposite was not seen. This higher migration capacity could maintain higher levels of gene flow among populations, diminishing differentiation levels.

\section{Hybridization}

Within each species, all samples had a very similar genetic composition: one most common allele/haplotype and some rare alleles/haplotypes. The most frequent haplotype of T. pallens was A while in T. reticulata, it was J. However, SRr-2, a T. reticutala sample, had haplotypes A and J at similar frequencies. This sample and SR-9 showed pallens alleles at two diagnostic allozyme loci, $P G I-1$ and $G 6 P D$, mostly in heterozygosis (Figure 2 ). This could be a sign of secondary hybridization but also of retention of ancestral polymorphism.

If species diverged recently, the shared haplotypes could be retention of ancestral polymorphism. The derived morphological characters would have arisen rapidly and recently, and this differentiation cannot be seen yet in mtDNA. Along time, random lineage extinctions would eliminate ancestral mtDNAs, while derived mtDNAs would be created by mutation. Thus, some individuals could be closer to members of other species than to their conspecifics, only due to particular patterns of survival and extinction of maternal lineage following the process of speciation (Tajima, 1983; Neigel and Avise, 1986). However, as signs of hybridization were also observed with the other marker, allozymes, the hypothesis of retention of ancestral polymorphism becomes a less probable alternative to explaining the genetic patterns observed.

Considering that we collected T. pallens and T. reticulata in sympatry in 2000, some successful interspecific matings could have occurred in Minas Gerais. If so, we would expect that SRr-2 should show stronger signs of hybridization than SR-9. This was indeed observed. The pattern is compatible with one hybridization season, when both spe- 
cies had contact, followed by backcrosses with $T$. reticulata, which caused a decrease in the frequency of the T. pallens genotype in this area over the years. Pie diagrams (Figures 2 and 3) show evidence of this decline along with the decrease in mean nucleotide diversity from 0.137 in 2000 to 0.074 in 2002 . Also, there was linkage disequilibrium in sample SR-2, indicating recent input of genotypes in this gene pool.

Most potential hybrids had a reticulata morphotype and haplotype A, which is the most frequent one in T. pallens. The rather low density of the invading T. pallens compared with the resident $T$. reticulata could have favored hybridization matings due to restricted mate choice (Hubbs' principle - Hubbs, 1955). If females were to remain unpaired, they would choose heterospecific mates. In a review of animal hybridization, Wirtz (1999) found support for this hypothesis and proposed that "hybrid matings are usually between the females of a rare species and the males of a common species, but not vice versa". Therefore, the rarer of the two parental species is the "mother species", whose mtDNA would pass to hybrids, as we observed.

Feder et al. (1999) described an event of hybridization between the cryptic species Rhagoletis zephyria and $R$. pomonella, also using allozymes and mtDNA restriction fragment length polymorphism. In these species, like in many other tephritid cryptic species, the reproductive isolating mechanism is the mating site. Usually, adult flies tend to mate and oviposit in the same host species in which they had fed as larvae (Feder and Filchak, 1999), which works as a reproductive barrier when close species have different hosts. Nevertheless, as $T$. reticulata and $T$. pallens parasitize the same host species, the mating site does not act as a barrier to them. Future studies may characterize courtship and ovipositing behavior of each species and clarify if there is also a behavioral barrier to mating. Anyway, this study indicates that sporadic hybridization events may not break down the phenotypic and genetic integrity of a species.

In conclusion, $T$. pallens and $T$. reticulata have the same host species and when their ranges overlap, a hybrid offspring can be produced. This hybridization seems to be a rare event, due to T. pallens unusual range expansion. As we probably documented a short period of sympatry, further investigation is needed to quantify the extent of gene flow between the two species. We cannot determine what caused this migration, but it could be related to an unusual rise in temperature, for example, as the species adapted to warmer environments migrated to a cooler one.

\section{ACKNOWLEDGMENTS}

We thank Horácio Montenegro for helping with the sampling of plants and Karla S.C. Yotoko for valuable comments. Research supported by CNPq (grant \#141539/2004-6 to A.G. Abreu) and FAPESP (grant \#98/05085-2 to Thomas M. Lewinsohn and \#04/097420 to V.N. Solferini).

\section{REFERENCES}

Abreu AG, Prado PI, Norrbom AL and Solferini VN (2005). Genetic and morphological diagnosis and description of two cryptic species of flower head-infesting Tephritidae (Diptera). Insect Syst. Evol. 36: 361-370.

Aluja M and Birke A (1993). Habitat use by adults of Anastrepha obliqua (Diptera: Tephritidae) in a mixed mango and tropical plum orchard. Ann. Entomol. Soc. Am. 86: 799-812. 
Avise JC (2000). Phylogeography: the History and Formation of Species. Harvard University Press, Cambridge.

Azeredo-Espin AML, Schroder RFW, Huettel M and Sheppard WS (1991). Mitochondrial DNA variation in geographic populations of Colorado potato beetle, Leptinotarsa decemlineata (Coleoptera; Chrysomelidae). Cell. Mol. Life Sci. 47: 483-485.

Bateman MA (1972). The ecology of fruit flies. Annu. Rev. Entomol. 17: 493-518.

Belkhir K, Borsa P, Chikhi L, Raufaste N, et al. (1996-2004). GENETIX 4.05, Logiciel Sous Windows TM Pour la Génétique des Populations. Laboratoire Génome, Populations, Interactions, CNRS UMR 5000, Université de Montpellier II, Montpellier.

Britten HB and Rust RW (1996). Population structure of a sand dune - obligate beetle, Eusattus muricatus, and its implications for dune management. Conserv. Biol. 10: 647-652.

Britten HB, MacClure AR, Tyler AM, Kattan AD, et al. (2003). Effects of host-plant distribution on genetic structuring of two tortoise beetles (Coleoptera: Chrysomelidae: Cassidinae) in the northern great plains. Ann. Entomol. Soc. Am. 96: 856-864.

Eber S, Sturm P and Brandl R (1991). Genetic and morphological variation among biotypes of Tephritis bardanae. Biochem. Syst. Ecol. 19: 549-557.

Evanno G, Regnaut S and Goudet J (2005). Detecting the number of clusters of individuals using the software STRUCTURE: a simulation study. Mol. Ecol. 14: 2611-2620.

Excoffier L, Laval G and Schneider S (2005). Arlequin (version 3.0): An integrated software package for population genetics data analysis. Evol. Bioinf. Online 1: 47-50.

Falush D, Stephens M and Pritchard JK (2007). Inference of population structure using multilocus genotype data: dominant markers and null alleles. Mol. Ecol. Notes 7: 574-578.

Feder JL and Filchak KE (1999). It's about time: the evidence for host plant-mediated selection in the apple maggot fly, Rhagoletis pomonella, and its implications for fitness trade-offs in phytophagous insects. Entomol. Exper. Applic. 91: 211-225.

Feder JL, Williams SM, Berlocher SH, McPheron BA, et al. (1999). The population genetics of the apple maggot fly, Rhagoletis pomonella and the snowberry maggot, R. zephyria: implications for models of sympatric speciation. Entomol. Exper. Applic. 90: 9-24.

Fitt GP (1986). The influence of a shortage of hosts on the specificity of oviposition behaviour in species of Dacus (Diptera, Tephritidae). Physiol. Entomol. 11: 113-143.

Headrick DH and Goeden RD (1998). The biology of nonfrugivorous tephritid fruit flies. Annu. Rev. Entomol. 43: 217-241.

Hubbs CL (1955). Hybridization between fish species in nature. Syst. Zool. 4: 1-20.

Johannesen J and Seitz A (2003). Comparative population genetic structures of the fruit fly Urophora cardui and its primary parasitoid Eurytoma robusta. Entomol. Exper. Applic. 108: 149-157.

Keyghobadi N, Roland J and Strobeck C (1999). Influence of landscape on the population genetic structure of the alpine butterfly Parnassius smintheus (Papilionidae). Mol. Ecol. 8: 1481-1495.

Kumar S, Tamura K and Nei M (2004). MEGA3: Integrated software for Molecular Evolutionary Genetics Analysis and sequence alignment. Brief. Bioinform. 5: 150-163.

MacLeish NFF (1987). Revision of Eremanthus (Compositae: Vernonieae). Ann. Missouri Bot. Gard. 74: 265-290.

McCauley DE (1987). Population genetic consequences of local colonization: evidence from the milkweed beetle Tetraopes tetraophtha. Fla. Entomol. 70: 21-30.

Mopper S and Strauss S (1998). Genetic Structure and Local Adaptation in Natural Insect Populations: Effects of Ecology, Life History, and Behavior. Chapman and Hall, New York.

Nei M (1978). Estimation of average heterozygosity and genetic distance from a small number of individuals. Genetics 89: $583-590$.

Nei M (1987). Molecular Evolutionary Genetics. Columbia University Press, New York.

Nei M and Li WH (1979). Mathematical model for studying genetic variation in terms of restriction endonucleases. Proc. Natl. Acad. Sci. U. S. A. 76: 5269-5273.

Neigel JE and Avise JC (1986). Phylogenetic Relationships of Mitochondrial DNA Under Various Demographic Models of Speciation. In: Evolutionary Processes and Theory (Nevo E and Karlin S, eds.). Academic Press, New York, 515-534.

Norrbom AL, Zucchi RA and Hernández-Ortiz V (1999). Phylogeny of the Genera Anastrepha and Toxotrypana (Trypetinae: Toxotrypanini) Based on Morphology. In: Fruit Flies (Tephritidae): Phylogeny and Evolution of Behavior (Aluja M and Norrbom AL, eds.). CRC Press, Boca Raton, 299-342.

Peschken DP and Harris P (1975). Host specificity and biology of Urophora cardui (Diptera: Tephritidae). A biocontrol agent for Canada thistle (Cirsium arvense). Can. Entomol. 114: 349-357.

Prado PI, Lewinsohn TM, Almeida AM, Norrbom AL, et al. (2002). The fauna of Tephritidae (Diptera) from capitula of 
Asteraceae in Brazil. Proc. Entomol. Soc. Wash. 104: 1007-1028.

Raymond M and Rousset F (1995). GENEPOP (version 1.2): Population genetics software for exact tests and ecumenicism. J. Heredity 86: 248-249.

Rizzini CT (1997). Tratado de Fitogeografia do Brasil: Aspectos Ecológicos, Sociológicos e Florísticos. Âmbito Cultural Edições Ltda., Rio de Janeiro.

Roland J, Keyghobadi N and Fownes S (2000). Alpine Parnassius butterfly dispersal: Effects of landscape and population size. Ecology 81: 1642-1653.

Simon C, Frati F, Beckenback A, Crespi B, et al. (1994). Evolution, weighting, and phylogenetic utility of mitochondrial gene sequences and a compilation of conserved polymerase chain reaction primers. Ann. Entomol. Soc. Am. 87: 651-701.

Straw NA (1989). The timing of oviposition and larval growth by two tephritid fly species in relation to host-plant development. Ecol. Entomol. 14: 443-454.

Tajima F (1983). Evolutionary relationship of DNA sequences in finite populations. Genetics 105: 437-460.

Weir BS and Cockerham CC (1984). Estimating F-statistics for the analysis of population structure. Evolution 38: 1358-1370.

Wirtz P (1999). Mother species-father species: unidirectional hybridization in animals with female choice. Anim. Behav. 58: $1-12$.

Wright S (1951). The genetical structure of populations. Ann. Eugen. 15: 323-354.

Zwölfer H (1982). Life Systems and Strategies of Resource Exploitation in Tephritids. In: Fruit Flies of Economic Importance (Cavalloro R, ed.). A.A. Balkema, Rotterdam, 16-30. 